\title{
Dimensões ideológicas do debate público acerca da violência no futebol brasileiro
}

CDD. 20.ed. 301.633

796.33

\section{Resumo}

Este estudo objetivou responder a seguinte indagação: em que medida e como os discursos enunciados no atual debate público sobre a violência no futebol brasileiro acerca do torcedor vinculado a atos violentos podem ser considerados ideológicos, estabelecendo e sustentando relações de dominação? Para responder a esta questão, o conceito de ideologia de John B. Thompson foi adotado, bem como a sua proposta metodológica: a hermenêutica de profundidade. Seguindo a estrutura tradicional dessa metodologia, o trabalho foi estruturado em três partes interdependentes: num primeiro momento, o contexto sócio-histórico do debate em questão foi analisado. Em seguida, sua estrutura formal ou discursiva. E, em um terceiro momento, essa estrutura foi interpretada à luz do contexto sócio-histórico. Com base na análise realizada, é possivel concluir que o referido debate adota uma narrativa que estigmatiza os torcedores vinculados a atos violentos e que essa narrativa atinge diretamente os torcedores organizados, mantendo-os em uma situação de dominação.

PalaVRaS-Chave: Futebol; Violência; Ideologia; Torcidas organizadas.

\section{Introdução}

A violência envolvendo torcedores de futebol, tanto nas arquibancadas como fora delas, não é recente. Sabe-se que esse fenômeno ocorre há décadas em várias partes do mundo, estendendo-se aos anos anteriores à Primeira Grande Guerra ${ }^{1}$ Entretanto, no Brasil, foi somente no final dos anos $80 \mathrm{e}$, principalmente, na primeira metade dos anos 90 , que, depois de uma série de graves incidentes, a violência no futebol ganhou uma dimensão pública maior. Desde então, diversos atores - como jornalistas, dirigentes esportivos, acadêmicos, autoridades públicas etc. - têm promovido uma ampla discussão sobre o assunto, realizada tanto nos meios de comunicação

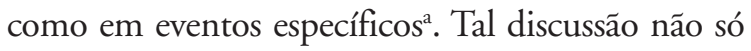
tem ajudado a sensibilizar a opinião pública quanto à extensão e gravidade do problema como, também, tem norteado as políticas de segurança para o espetáculo futebolístico.

Diante da relevância e premência desse debate, considero ser fundamental o desenvolvimento de pesquisas científicas que visem problematizar o modo como ele tem sido construído. Neste artigo, optei por focalizar o tratamento dado ao torcedor vinculado a açóes consideradas violentas. Ou seja, ao invés de abordar como a sociedade constrói torcedores violentos, optei por abordar como ela constrói a categoria "torcedor violento" e a incorpora como tema de relevo. Ao fazer isto, minha intenção não é comparar a construção dessa categoria com a "verdade" a respeito desse torcedor, uma vez que parto do pressuposto de que não existe uma verdade em si, independente dos enunciados que a linguagem nos permite construir para representar o mundo ${ }^{2}$. Tratase sim de refletir sobre as implicações ideológicas dos sentidos mobilizados por tal categoria. Mais concretamente, trata-se de responder a seguinte indagação: se, em que medida e como os discursos enunciados no debate público sobre a violência no futebol brasileiro acerca do torcedor vinculado a atos violentos podem ser considerados ideológicos, estabelecendo e sustentando relaçôes de dominação? Antes de começar a responder essa pergunta, é preciso, todavia, apresentar e justificar o conceito de ideologia que fundamenta e orienta este trabalho. 


\section{$O$ conceito de ideologia}

O conceito de ideologia utilizado aqui é o desenvolvido por John B. THOMPSON ${ }^{3}$, em "Ideologia e Cultura Moderna”. Nesta obra, o autor retraça os contornos históricos do referido conceito, "[...] com a intenção não apenas de realçar as reviravoltas e escaramuças de um itinerário intelectual complexo, mas, também, para preparar caminho para um enfoque mais construtivo" (p.43). Ao retraçar esses contornos históricos, Thompson distingue dois tipos gerais de concepção de ideologia: a neutra e a crítica. A primeira delas compreende a ideologia como uma forma de investigação social ou como um aspecto da vida social como outro qualquer, não sendo nem mais nem menos atraente ou problemático. Já a segunda imputa aos fenômenos caracterizados como ideológicos um criticismo implícito ou sua própria condenação.

A concepção de ideologia proposta por THOMP$\mathrm{SON}^{3}$ insere-se nesse segundo grupo. No entanto, embora se apoie nas conceituações críticas anteriores, sua formulação abandona alguns dos temas nelas implícitos. Ao fazer isto, o autor propõe uma conceituação de ideologia ao mesmo tempo construtiva - uma vez que procura elaborar um novo conceito de ideologia, ao invés de restituir algum anterior - e modesta - uma vez que não tenta realizar uma síntese das diversas concepçôes de ideologia, como se o desenvolvimento histórico do conceito desembocasse naturalmente numa concepção definitiva.

Essa proposta conceitual de THOMPSON ${ }^{3}$ objetivase em uma definição relativamente ampla de ideologia, que a compreende como o "sentido a serviço da dominação". A fim de precisar tal definição, o autor destaca que uma situação pode ser descrita como de dominação quando relações de poder são sistematicamente assimétricas, ou seja, "[...] quando grupos particulares de agentes possuem poder de uma maneira permanente, e em grau significativo, permanecendo inacessível a outros agentes, ou a grupos de agentes, independentemente da base sobre a qual tal exclusão é levada a efeito" (p.80).

A partir dessa concepção de ideologia, uma forma simbólica será ideológica quando, em um contexto sócio-histórico determinado, estabelecer e sustentar relações de dominação. Inversamente, será contestatória ou crítica da ideologia quando ajudar a minar essas relações. Assim, a interpretação do potencial ideológico ou contestatório de uma forma simbólica deve explicitar o vínculo entre os sentidos mobilizados por ela e as relações de dominação que esses sentidos mantêm ou subvertem. Deve, portanto, considerar os contextos sócio-históricos específicos nos quais essa forma simbólica é produzida, transmitida e recebida ${ }^{\mathrm{b}}$.

Ao considerar a importância desses contextos na interpretação da ideologia, a proposta analítica de THOMPSON $^{3}$ nos permite evitar uma tendência, prevalente na literatura, de pensar a ideologia como uma característica ou atributo intrínseco de certas formas simbólicas ou sistemas simbólicos - tais como o conservadorismo, o comunismo e o liberalismo. Em sua proposta, nenhuma forma simbólica é ideológica ou contestatória em si mesma: se ela é ideológica ou contestatória, e o quanto o é, isto depende da maneira como é usada e entendida em contextos sociais específicos. Diante disto, uma forma simbólica poderá ser considerada como ideológica num contexto e como subversiva noutro, bem como poderá ser considerada ideológica sob certos aspectos e contestatória sob outros. Por exemplo, ela poderá sustentar relações de dominação de gênero e, ao mesmo tempo, minar relaçôes de dominação de classe.

Além de evitar a tendência supracitada, a conceituação de ideologia proposta por THOMPSON ${ }^{3}$ é analiticamente pertinente para este trabalho porque, ao mesmo tempo em que imputa aos fenômenos caracterizados como ideológicos um criticismo implícito e sua própria condenação, rechaça a ideia de que toda ideologia seja intrinsecamente ilusória colocando seu caráter enganador apenas como uma possibilidade contingente. Com isso, o autor evita que a análise da ideologia seja conduzida, ainda que implicitamente, pela problemática noção de "falsa consciência". Afinal, assume uma concepção política de ideologia - uma vez que traz para o seu âmago a questão da dominação - e não epistemológica - uma vez que nada diz acerca da questão da verdade, ou melhor, de como se conhece o mundo social.

Outra vantagem analítica da proposta de THOMP$\mathrm{SON}^{3}$ para este trabalho é o fato de ela não colocar a ideologia como necessariamente dependente das relações de dominação de classe. Pelo contrário, sua concepção de ideologia caracteriza-se justamente por uma abertura à análise da força simbólica de outras formas de dominação, derivadas ou não das relações de produção. Afinal, para o autor, "[...] relaçōes de classe são apenas uma forma de dominação e subordinação, constituem apenas um eixo da desigualdade e exploração; as relações de classe não são, de modo algum, a única forma de dominação e subordinaçáo" (p. 77, grifos do autor). Assim, ao abrir-se para outras formas de dominação, a referida 
conceituação faculta-me discutir ideologia(s) no debate público acerca da violência no futebol brasileiro sem, no entanto, reduzi-la(s) a mero(s) reflexo(s) das estruturas econômicas e sociais.

Por fim, cabe notar que, ao indicar e investigar diversos modos de operação da ideologia, THOMPSON ${ }^{3}$ também me oferece um rico campo de investigação das estratégias de construção simbólica empregadas no debate em questão. Com isso, oferece-me instrumentos analíticos que me facultam "desevidenciar" o fundo discursivo desse debate, explicitando seus implícitos e avançando nas suas consequências lógicas e sociais ${ }^{4}$.

\section{Contexto de produção, transmissão e recepção do debate}

Para compreendermos o debate público acerca da violência no futebol brasileiro, é preciso termos em mente que ele ocorre dentro de um universo socialmente estruturado, ou seja, marcado por assimetrias, divisões e diferenças coletivas relativamente estáveis ${ }^{3}$. A distribuição e o acesso a recursos, poder, oportunidades e possibilidades de realização não são iguais para cada grupo envolvido. Em geral, autoridades públicas, dirigentes esportivos, acadêmicos e jornalistas são incluídos nos lugares e situaçôes legítimas de enunciação do discurso. Com isso, conseguem fazerse escutar mais do que outros, tendo mais chances de intervir no curso do debate e em suas consequências.

Já a possibilidade de um torcedor organizado tomar a palavra e ser ouvido parece ser bem menor. Trata-se de locutores ilegítimos, que nem sempre possuem a oportunidade de se dirigir a destinatários legítimos, reconhecidos e reconhecedores. Mais ainda, trata-se de locutores que, quando possuem tal oportunidade, frequentemente têm de se comunicar a partir de lugares ilegítimos - como, por exemplo, num seminário, a partir da plateia e não da mesa de discussão "(lugar de onde se fala com autoridade)" . Isto possui implicaçōes profundas, como a perda de parte da força simbólica de suas declarações e denúncias. Afinal, o valor simbólico de um discurso tende a ser definido em função do prestígio que seus receptores conferem a quem o enuncia e ao lugar onde é enunciado ${ }^{3}$.

O fato de os torcedores possuírem um poder reduzido de intervenção nos rumos do debate não quer dizer, todavia, que eles não constituam um mecanismo de pressão atuante. Pelo contrário, eles assumem um espaço cada vez maior no estádio e na sociedade ${ }^{6}$. Por exemplo, foram emblemáticas as greves, piquetes e boicotes promovidos pelas torcidas organizadas cariocas, ainda no início dos anos 80, para exigir, entre outras coisas, a diminuição do preço das entradas ${ }^{\mathrm{c} 7}$. Foi igualmente emblemática a greve promovida, em 1978, pela Torcida Uniformizada do Palmeiras (TUP) contra os desmandos da diretoria do clube, assim como as críticas da Torcida Jovem, do
Santos, à formula do Campeonato Paulista de 1981. Ou ainda, o apoio dado pelos Gaviōes da Fiel, do Corinthians, à anistia ampla e irrestrita no Brasil, no final da década de $70^{8-9}$. Mais recentemente, temos diversos outros exemplos de lutas e reivindicaçōes feitas pelas torcidas organizadas. Entre elas, a campanha realizada, em 2007, pelas torcidas corintianas contra o então presidente do clube, Alberto Dualib, e seu vice, Nesi Curi, acusados de lavagem de dinheiro e formação de quadrilha pelo Ministério Público Federal, no período da parceria Corinthians/ Media Sports Investiment (MSI). No entanto, este histórico de lutas e reivindicações tem sido, algumas vezes, ofuscado por conflitos violentos, que acabaram se tornando parte da história das torcidas organizadas.

\section{Torcidas organizadas}

As primeiras torcidas organizadas surgiram em São Paulo e no Rio de Janeiro, no final da década de 60 e início da década de 70, quando o Brasil ainda enfrentava a forte repressão do regime militar, ao mesmo tempo em que se desenvolvia economicamente. Neste período, alguns grupos de jovens torcedores começaram a se reunir nas arquibancadas para criticar os abusos e desmandos de autoridades e dirigentes esportivos. Isto é, as torcidas organizadas não nasceram com o propósito de promover a violência, mas sim com o objetivo de ocupar um espaço político até então não reivindicado pelos torcedores em geral 5 . Hoje em dia, os torcedores organizados são uns dos principais responsáveis por transformar o espetáculo futebolístico em uma experiência audiovisual colorida, ruidosa e excitante, levando faixas, bandeiras e instrumentos de percussão para os estádios. Além disso, são facilmente identificados pelas suas vestimentas, coreografia e cânticos de guerra próprios ${ }^{6}$.

Embora desde a década de 40 já houvesse, no Rio de Janeiro, alguns grupos de torcedores que se autointitulavam torcidas organizadas ${ }^{\mathrm{d}} \mathrm{e}$, ainda que esses grupos, assim como outros agrupamentos de 
torcedores do período ${ }^{\mathrm{e}}$, já tivessem o hábito de planejar os espetáculos nas arquibancadas com antecedência e de acompanhar o clube apoiado em praticamente todos os lugares, não podemos confundi-los com os atuais torcedores organizados ${ }^{10}$. Afinal, a identificação de seus integrantes se dava apenas com o clube apoiado, e não, também, com o próprio agrupamento. Além do mais, esses grupos não tinham uma estrutura burocrática - seus vínculos se davam diretamente com o clube de futebol, que muitas vezes financiava suas despesas - e ainda estavam muito associados a "torcedores símbolos", que representavam toda a torcida e possuíam grande prestígio na imprensa ${ }^{11}$.

Outra diferença significativa entre esses agrupamentos de torcedores e os integrantes das atuais torcidas organizadas é que os primeiros raramente se envolviam em confusão, o que fazia com que a imprensa esportiva da época os percebesse como um núcleo civilizado no meio da massa, que inibia o mau comportamento de outros torcedores ${ }^{11}$. Os segundos, por sua vez, vêm sendo progressivamente associados ao vandalismo e à barbárie ocorridos dentro e fora dos estádios brasileiros - tanto que, na década de 80 , os meios de comunicação os alçaram à condição de problema social, convertendo-os em objeto de preocupação pública constante. Isto se deu, sobretudo, a partir de 1988, com a ampla cobertura dada ao assassinato de um dos dirigentes e fundadores da Mancha-Verde, uma das principais torcidas organizadas do Palmeiras do período ${ }^{\mathrm{f5}}$.

$\mathrm{Na}$ década seguinte, as torcidas organizadas cresceram significativamente, ampliando - e muito - o número de associados. De 1991 a 1995, as principais torcidas organizadas de São Paulo, por exemplo, quadriplicaram o seu quadro associativo: a Mancha-Verde saltou de 4.000 filiados para 18.000, a Independente de 7.000 para 28.000 e os Gaviōes da Fiel de 12.000 para $46.000^{6}$. Em meados da década de 90 , os torcedores organizados e a violência no futebol brasileiro ganharam uma dimensão pública ainda maior. Um episódio em especial parece ter chamado a atenção da imprensa, recebendo ampla cobertura jornalística: a chamada "batalha campal do Pacaembu", quando torcedores do Palmeiras e do São Paulo invadiram o gramado e se enfrentaram violentamente com paus, pedras e outros artefatos, resultando na morte de um torcedor e numa centena de feridos. A partir de então, o poder público começou a tomar uma série de providências a fim de combater a violência no futebol.

Todavia, essas medidas não impediram que novos confrontos acontecessem na última década. Pelo contrário, nesse período, o número de mortes de torcedores sofreu um aumento substancial. De acordo com a pesquisa L!-Ibope ${ }^{13}$, publicada em agosto 2010, das 51 mortes ocorridas no futebol brasileirog até então, $41(80 \%)$ delas ocorreram na primeira década deste século. Segundo esse estudo, é nesse período também que os homicídios ligados ao futebol, antes mais concentrados em São Paulo, espalham-se pelo país ${ }^{\mathrm{h}}$.

\section{Políticas de segurança}

A fim de conter esse avanço da violência, uma série de medidas de segurança tem sido adotada nos últimos anos. Hoje em dia, um dos mais importantes instrumentos legais de proteção e defesa do torcedor é a Lei ${ }^{\circ} 10.671 / 03$, mais conhecida como Estatuto de Defesa do Torcedor ${ }^{13}$. Sua entrada em vigor foi um marco na história esportiva do país, afinal, "[...] apesar de o futebol já ter chegado ao país em forma de espetáculo, de ser há duas décadas uma das mercadorias mais rentáveis do capitalismo, no país até 2003 não havia leis que regulamentassem a promoção do esporte como espetáculo" ${ }^{14}$ (p.98). O Estatuto de Defesa do Torcedor foi inicialmente proposto, em 2002, pela Comissão de Educação Cultura e Desporto da Câmara dos Deputados como projeto de Lei $\mathrm{n}^{\circ} 7.262 / 02$. Depois tramitou no Senado Federal como Projeto de Lei $n^{\circ} 1 / 03$, sendo sancionado pelo então Presidente da República, Luiz Inácio Lula da Silva, em 15/05/ 2003.

Recentemente, esse estatuto passou por algumas modificações. Em 27 de julho de 2010, foi sancionada a Lei no 12.299/2010, que buscou complementálo. Algumas das modificações causaram e seguem causando polêmica. Entre elas, o Art. 39-B, que responsabiliza civilmente as torcidas organizadas pelos danos provocados por seus associados nos locais do evento esportivo, em suas imediações ou nos trajetos de ida e volta ${ }^{15}$. Outra medida que causou muita discussão e questionamento - ao menos nos meios de comunicação - foi a de realizar um cadastramento nacional dos torcedores, o que, a princípio, dificultaria a ação dos cambistasi. Tal proposta foi anunciada, em 2009, pelo então ministro do Esporte, Orlando Silva, junto a uma série de outras providências batizadas de "Torcida Legal", conforme divulgaram os meios de comunicação na épocaj. No entanto, depois de receber inúmeras críticas, ela acabou sendo descartada.

Além do Estatuto de Defesa do Torcedor, existe uma série de medidas pontuais sendo adotada nos estádios dos diversos estados do país. A Federação Paulista de Futebol (FPF), por exemplo, baseando-se no relatório 
da Comissão Paz no Esporte ${ }^{16}$ dos ministérios do Esporte e da Justiça, adotou um projeto piloto para o Campeonato Paulista de 2007, implementando uma série de ações que são válidas até hoje. Entre outras ações, esse relatório recomendou que as torcidas organizadas ocupassem um espaço de destinação específica para elas, não permitindo que, em outros lugares do estádio, haja circulação de torcedores portando qualquer forma de identificação de torcida organizada. Para adentrar tais espaços, ficou definido que o torcedor teria de possuir o "cartão torcedor", obtido através de seu cadastramento na FPF.

O Ministério Público do Estado de São Paulo, bem como o de Minas Gerais, também determinou que todas as torcidas organizadas de seu Estado

\section{Método}

Partindo da perspectiva de que a metodologia não tem "status" próprio, mas precisa ser definida em função de um contexto teórico-metodológico determinado $^{18}$, adotei não apenas a conceituação de ideologia do Thompson ${ }^{3}$, mas, também, sua proposta metodológica: a hermenêutica de profundidade. Esta busca contemplar tanto as características estruturais das formas simbólicas quanto suas condições sócio-históricas. Para tanto, compreende três etapas, "[...] que devem ser vistas não como estágios separados de um método sequencial, mas antes como dimensões analiticamente distintas de um processo interpretativo complexo" (p.365). A primeira delas é a análise sócio-histórica, que objetiva "[...] reconstruir as condições sociais e históricas de produção, circulação e recepção das formas simbólicas" (p.366). A segunda é análise formal ou discursiva, que busca estudar as formas simbólicas como "[...] construções simbólicas complexas que apresentam uma estrutura articulada” (p.34). E a terceira é a interpretação/reinterpretação, que se interessa "[...] pela explicitação criativa do que é dito ou representado pela forma simbólica” (p.34).

\section{Constituição do "corpus"}

Uma vez apresentada a estrutura da hermenêutica de profundidade, cabe, agora, relatar como foi constituído o "corpus" da pesquisa. A fim de obter narrativas que fossem representativas e significativas dos diversos atores envolvidos no debate público acerca da violência no futebol brasileiro, busquei devem possuir CNPJ, registrar o estatuto da entidade em cartório, fazer seu registro na federação local, bem como orientar seus associados a realizar o cadastramento individual para obtenção do "cartão torcedor”. Mais recentemente, desde o final de 2011, também passou a vigorar em São Paulo a Lei $\mathrm{n}^{\circ}$ 14.590, que determinou, entre outras coisas, que "os estabelecimentos que realizam a venda de ingressos para as partidas oficiais de futebol deverão identificar os respectivos compradores" ${ }^{17}$. Esta e as outras medidas de segurança apresentadas aqui têm alimentado o debate em questão, ao mesmo tempo em que têm sido influenciadas por ele. Antes de começar a analisar os discursos nele enunciados, é importante apresentar e justificar a metodologia empregada no trabalho.

material sobre o tema em documentos de domínio público, ou seja, em produtos sociais tornados públicos. De acordo com Peter SPINK ${ }^{19}$, esses documentos possuem grande potencial de circulação de sentidos e de reestruturação dos espaços institucionalizados de interação. Além disto,

eticamente estão abertos para análise por pertencerem ao espaço público, por terem sido tornados públicos de uma forma que permite a responsabilização. Podem refletir as transformações lentas em posições e posturas institucionais assumidas pelos aparelhos simbólicos que permeiam o dia-a-dia, ou, no âmbito das redes sociais, pelos argumentos e coletivos que dão forma ao informal, refletindo o ir e vir de versões circulantes assumidas ou advogadas ${ }^{19}$ (p.136).

Os documentos de domínio público podem assumir diversas formas, tais como diários oficiais, arquivos variados, jornais e revistas, anúncios, publicidade, manuais de instrução, relatórios anuais etc. Nesta pesquisa, trabalhei com textos opinativos publicados em jornais de grande circulação - mais exatamente, a Folha de S. Paulo e o diário esportivo Lance! - uma vez que a chamada "grande imprensa" constitui um "lócus" privilegiado para o debate público em torno de problemas sociais. Meu acesso aos textos jornalísticos opinativos se deu por meio de um levantamento no banco virtual de dados da Folha de S. Paulo, no Arquivo Público do Estado de São Paulo e no meu arquivo pessoal ${ }^{\mathrm{k}}$.

Neste levantamento, selecionei textos publicados entre 2009 e 2010, uma vez que, no referido período, o debate público em torno da violência no futebol 
brasileiro acentuou-se. Entre outras razōes, isto se deveu a alguns episódios marcantes de violência como o ocorrido na última rodada do Campeonato Brasileiro de 2009 - e à sanção da Lei no 12.229 , em 27 de julho de 2010, que modificou o Estatuto de Defesa do Torcedor. Por meio deste levantamento, tive acesso a textos de jornalistas, autoridades públicas, acadêmicos e de dirigentes esportivos e acabei selecionando um total de 62 artigos.

Entre estes, há tanto editoriais quanto artigos e colunas de opinião. Enquanto os editoriais manifestam os princípios gerais e as teses orgânicas do jornal, os artigos e as colunas de opinião são produzidos por colaboradores ou convidados - em geral, personalidades e especialistas - e não traduzem necessariamente a opinião do jornal. Grosso modo, pode-se dizer que o editorial é a opiniāo do jornal, enquanto que os artigos e colunas de opinião são opiniões que são publicadas e podem ser lidas no jornal'. Deste modo, diferentemente dos artigos e colunas de opiniāo, o editorial possui representatividade institucional.

\section{Procedimentos de análise e interpretação do "corpus"}

Para realizar a análise sócio-histórica dos textos selecionados, fiz um levantamento bibliográfico acerca do tema da violência no futebol brasileiro em nove bases de dados ${ }^{\mathrm{m}}$. Nesta revisão, encontrei, entre outras produções, três teses de doutorado e 22 dissertaçōes de mestrado, sendo que nenhuma delas era anterior à década de 90 , o que sugere certa defasagem temporal entre essa produção e a veiculação da referida violência na mídia, intensificada a partir da década de 80, conforme dito anteriormente. Ainda que de forma bastante resumida, os resultados desse levantamento foram apresentados anteriormente no tópico "contexto de produção, transmissão e recepção do debate". Para realizar a análise formal ou discursiva desses textos, deduzi de cada um deles as proposições que expressam as ideias centrais acerca dos torcedores vinculados a atos violentos. Por seu caráter de síntese, chamei essas proposiçôes de macroproposiçôes ${ }^{20-21}$. Em seguida, agrupei essas macroproposiçôes por temas e analisei as estratégias de construção simbólica empregadas na construção de cada uma delas. Para tanto, realizei uma discussão acerca, entre outras coisas, da sintaxe, das escolhas léxicas e das figuras retóricas utilizadas. Para realizar a interpretação/reinterpretação do material, fiz uma síntese, por construção criativa, dos resultados das duas etapas anteriores. Isto é, busquei explicitar as conexôes possíveis entre os sentidos mobilizados pelos textos analisados na segunda etapa e as relações de dominação que estruturam o contexto analisado na primeira etapa.

\section{Análise formal ou discursiva do debate}

Antes de analisar propriamente a organização discursiva interna dos artigos selecionados - suas características estruturais, seus padrões e relações -, cabe traçar um panorama geral desses textos. A grande maioria deles foi publicada logo após a ocorrência de graves incidentes de violência, o que é indicativo de que o debate público sobre o tema (ao menos aquele que acontece na mídia) é, basicamente, reativo: espera a violência eclodir para ocorrer. Também é interessante observar que não encontrei nenhum texto assinado por torcedores organizados, o que reforça a percepção de que esses torcedores não possuem voz nos meios de comunicação e, consequentemente, em um importante espaço onde tal debate acontece. No período analisado, os jornais consultados abriram suas páginas para pessoas do dito "establishment" (sobretudo para seus articulistas), que, ao se associarem ao tema da violência, provavelmente ganharam visibilidade pública com ele ao mesmo tempo em que o valorizaram ${ }^{4}$. Este grupo relativamente homogêneo de autores talvez explique o motivo de certos discursos serem amplamente predominantes, ainda que não possa deixar de destacar a existência de algum grau de dissenso no material analisado. Para uma melhor exposição dos principais pontos de vista presentes nesse material, segui a categorização temática realizada de suas macroproposições.

\section{Construção simbólica dos torcedores vinculados a atos violentos}

Ainda que em diferentes níveis, praticamente todos os textos analisados dirigem forças de oposição ao torcedor vinculado a atos violentos. De um modo geral, ele é qualificado através de categorias depreciativas como "vândalo", "baderneiro", "vagabundo" e "marginal", conforme exemplificam os seguintes trechos: "Vândalos, baderneiros, como queiram chamar, 
protagonizaram cenas de guerra em um estádio de futebol"22 (grifos meus). "Além da guerra urbana e da ida dos marginais para os estádios, a violência dentro e fora dos campos ocorre [...]"23 (grifo meu). "A praça é dos vândalos assim como o céu é do monóxido de carbono"24 (grifo meu). "Sem medidas duras para conter a ação dos baderneiros, nossos estádios estão condenados a ficar cada vez mais vazios" 25 - (grifo meu). "[...] são raros os vagabundos que têm interesse em futebol"26 (grifo meu). "[...] 'o anonimato' [...] estimula a ação de baderneiros, aumentando a possibilidade de confrontos"27 (grifo meu). "Não faz muito tempo, a sala da diretoria do Palmeiras foi invadida por vândalos que quebraram o que viram pela frente" 28 (grifo meu). "[...] foram presos 15 marginais que criaram atos de barbárie após o jogo entre Coritiba e Fluminense, pela última rodada do último Campeonato Brasileiro"29 (grifo meu).

Além de sugerirem menosprezo pelo torcedor vinculado a atos violentos, essas categorias vinculam-no única e exclusivamente à sua condição de delinquente. Com isso, contaminam toda a sua identidade social com a marca de apenas um de seus comportamentos: aquele que é visto como desviante. Tal torcedor não faria apenas coisas ruins, mas seria essencialmente ruim: espécie de encarnação da violência. Nesse sentido, ele é construído de tal modo que sua "maldade" é naturalizada. Esta naturalização da maldade é reforçada no e pelo material analisado na medida em que muitos dos discursos nele enunciados não informam sobre os contextos psicossociais e socioeconômicos em que o torcedor em questão está inserido. Ao passarem por cima das condições históricas, sociais e culturais que mobilizam à sua (suposta) agressividade, esses discursos levam a crer que ela é "sem propósito" - sinalizando uma "maldade inata". Assim, tal torcedor seria mau, perigoso e ameaçador. Um sujeito incapaz de sentir algo que não seja ódio e raiva. Tratar-se-ia, portanto, não de um ser humano complexo - dotado de potencialidades, limitaçóes e defeitos -, mas de um inimigo, contra o qual somos chamados a resistir ou a expurgar.

O expurgo do outro se sobrepõe, na maioria das vezes, à estratégia da diferenciação na construção desse "inimigo", segmentando-o do conjunto da sociedade $^{3}$. Em alguns textos, o uso repetido do pronome da primeira pessoa no plural cria uma polarização entre um "nós", sociedade, e um "eles", torcedor violento, conforme ilustra o exemplo a seguir: "Nós precisamos de medidas efetivas para apurar... O que nós precisamos é de um processo investigativo para saber..."30. Essa polarização traz duas consequências: faz crer que esse torcedor não participa da sociedade e que ele constitui uma ameaça a ela. Ou seja, imprime-lhe as marcas da diferença e da ameaça, estigmatizando-o.

Por vezes, tal estigma opera negando a própria condição de torcedor do torcedor vinculado a atos de violência, como se comportar-se pacificamente fosse condição necessária para ser torcedor. O exemplo a seguir é ilustrativo: "o país ressente-se também de leis duras para conter e punir os vândalos, camuflados de torcedores" 25 . Aqui, podemos notar novamente o emprego da estratégia da diferenciação, que é expressa através do adjetivo "camuflados". Este faz crer que os torcedores vândalos não participam efetivamente da coletividade torcedora, construindo uma dicotomia entre ser vândalo e ser "torcedor de verdade".

\section{Identificação com os torcedores organizados}

Embora alguns textos reconheçam que as torcidas organizadas constituam instituições multifacetadas e que, frequentemente, seus integrantes são estigmatizados pela mídia e pela opinião pública, são comuns os discursos que fundem os torcedores organizados e os torcedores violentos numa mesma figura, colocando a violência como um elemento consubstancial também aos primeiros. Uma vez que essa associação contribui para tirar de cena o torcedor que se envolve em ações violentas e que não é filiado à torcida organizada, colocando-o na penumbra, pode-se dizer que, de partida, ela é dissimuladora. Mas ela também é abusiva, já que a identidade do torcedor organizado pacífico é contagiada pela ação violenta de alguns torcedores organizados. Em última instância, tal contaminação reveste todos os torcedores organizados com a imagem da violência e da delinquência.

Entre outras formas, esta contaminação é realizada através do uso de uma série de categorias depreciativas empregadas para identificar os torcedores organizados. Os fragmentos a seguir são ilustrativos: "O presidente do Corinthians deu um grande número de ingressos para o jogo de domingo para a turma barra-pesada [...]"23 (grifo meu). "Porque faltam inteligência, prevenção, repressão e punição para tratar da violência entre as gangues travestidas de torcedores de futebol [...]"31 (grifo meu). "O problema é que, por causa de meia dúzia de bandidos organizados, imagens como as duas fotos menores [de um ônibus em chamas e de uma fila de torcedores presos], também ao lado, aterrorizam os apaixonados pela bola"32 (grifo meu). "O futebol é sinônimo de alegria, arte, entretenimento, e não lugar para alguns bandos ou facçóes, como queiram, extrapolarem 
suas frustrações em forma de violência e até com técnicas terroristas"33 (grifo meu). "Aí sim, tanto o clube no seu envolvimento com as facçóes organizadas, quanto alguns de seus torcedores, talvez pensassem um pouco mais antes de cometer tais absurdos" ${ }^{44}$ (grifo meu). "Há um projeto de lei para que seja considerado crime quando o torcedor estiver indo ao estádio portando paus e barras de ferro, como aconteceu. Por esse projeto, a facção poderia ser responsabilizada criminalmente e até punida" ${ }^{35}$ (grifo meu). "E as gangues travestidas de torcidas são o maior impulso dessa violência"28 (grifo meu).

Nos trechos destacados no parágrafo anterior, expressōes como "turma barra-pesada", "gangues", "bandidos organizados", "facção" e "facções organizadas" reduzem as torcidas organizadas à sua dimensão violenta e contraventora e levam o leitor a fazer inferências desfavoráveis em relação aos integrantes dessas torcidas e, consequentemente, a considerar a necessidade de modificar o sistema de segurança, controle e sanção desses torcedores. Além disto, reúnem os torcedores organizados em grupos informes, apagando as diferenças e divisōes que existem entre eles. Nesse sentido, pode-se dizer que elas despersonalizam esses torcedores, consolidando sua identidade social deteriorada em detrimento de sua identidade pessoal ${ }^{36}$. Ao fazerem isto, ao mesmo tempo em que reduzem a singularidade de cada torcedor organizado, exacerbam a diferença de todos eles em relação ao resto da sociedade, sobreestimando a diferença "deles" em relação a "nós".

Podemos compreender este processo de identificação interna e distinção externa como uma expressão particular de um processo maior de estigmatização: de um lado, temos um grupo rotulado de "desviante" e, de outro, os admitidos como "normais". Essa contraposição é, amiúde, reforçada com o uso repetido da primeira pessoa do plural aliado ao uso repetido da terceira do plural, estratégia mencionada anteriormente: "Uma das cenas mais impressionantes do domingo passado foi o canto 'a violência voltou'. Não nos avisaram se algum dia ela foi embora, mas, pelo visto, os uniformizados tiveram essa impressão"37.

Outra estratégia empregada em alguns textos para desqualificar os torcedores organizados é a da dissimulação da sua dimensão social e política, que é realizada de diversas formas. Por exemplo, desviando a atenção do leitor para outras dimensôes, como ocorre quando os torcedores organizados são chamados de "torcedores uniformizados", categoria que privilegia sua dimensão estética e visual. Enquanto "organizado" remete à ideia de uma instituição estruturada, que age de maneira regular e que possui interesses sociais, políticos etc., "uniformizados" remete ao tipo de vestuário (padronizado e distintivo) utilizado por esses torcedores. Outra forma de dissimular a dimensão social e política desses torcedores é negando-a, como ocorre quando o adjetivo "organizados" é colocado entre aspas - o que sugere que a ideia de organização não coincide com o que esses torcedores realmente são -, tal como faz o jornalista Juca KFouR ${ }^{38}$ : “assim são os 'organizados', capazes, como fez também certa vez a Gaviōes da Fiel, de entoar em coro 'ê, ê, ê, o Juca vai morrê"'.

Alguns textos também sugerem que os torcedores organizados são "privilegiados". Os trechos a seguir são ilustrativos: "foram décadas de distribuição gratuita de ingressos, de financiamento de viagens, bandeiras e uniformes. Privilégios que os sócios legítimos, que pagam em dia suas mensalidades, que contribuem para sustentar o futebol, nunca tiveram o direito de desfrutar"28. "[As torcidas organizadas] contam com uma série de privilégios concedidos pelos clubes (ingressos facilitados, ajuda com transporte, participação em reuniōes de direção) e até pela PM, que escolta seus membros na entrada ao estádio em dias de jogos" 39 . Ainda que existam indicativos de que, muitas vezes, isto realmente ocorra, compreendo o uso do termo "privilégios" aqui como um eufemismo, que dissimula certos aspectos da realidade desses torcedores. Afinal, como já foi dito, eles possuem uma série de obrigaçôes que outros torcedores não possuem. Além do mais, a escolta da polícia serve não apenas para protegê-los, mas, sobretudo, para vigiá-los. Nesse sentido, ela é mais um mecanismo de controle do que propriamente um privilégio. Também é preciso lembrar que esses torcedores carecem, de fato, de mais proteção do que os outros torcedores, uma vez que eles são o principal alvo de emboscadas de torcedores rivais.

Em alguns textos, os ditos "privilégios" oferecidos pelas diretorias dos clubes aos torcedores organizados fariam de ambos os grupos parceiros. Invariavelmente, essa parceria é qualificada negativamente, seja através de adjetivos como "inadmissível" e "perigosa" seja sendo substantivada através, por exemplo, do termo "cumplicidade", que a reveste com a imagem do crime. Em todos esses casos, a identidade dos dirigentes esportivos é contagiada pelo vínculo com os torcedores organizados. "É um verdadeiro pacto com o diabo", sentencia Benjamin BACK ${ }^{40}$. Esse contágio é um dos efeitos típicos do estigma: aquele que convive com o estigmatizado tende a ser estigmatizado também. Isto fica particularmente claro no trecho em que o 
referido autor ${ }^{40}$ escreve que "o mínimo que se espera de um dirigente é que ele seja sério e que não crie vínculos com torcidas organizadas”.

Outro efeito típico do estigma mobilizado pelo material analisado é a legitimação do exercício do controle social sobre o estigmatizado. $\mathrm{O}$ artigo de Luis Fernando Gomes ${ }^{28}$, por exemplo, afirma que: felizmente, há quem tenha acordado. Vez por outra há recaídas como as citadas aqui, que atrasam a transformação. Mas os programas de sócio-torcedores dos clubes - Grêmio e Inter à frente - têm mudado essa relação, pendido a balança para quem só quer torcer de verdade. Depois da barbárie que interditou o Couto Pereira, o Coritiba foi ainda mais longe: proibiu símbolos de organizadas nos seus jogos e, na medida do que a legislação permite, tenta restringir a presença dos vândalos em campo.

Finalmente, alguns textos argumentam que as torcidas organizadas são, na verdade, reflexo da sociedade: "ambientadas e nutridas nas dinâmicas de poder, as organizadas reproduzem os sucessos e fracassos das organizações sociais que conformam o que visualizamos por sociedade" ${ }^{41}$. Em certa medida, tal argumento desloca a responsabilidade das ações dos torcedores organizados para o conjunto da sociedade.

\section{Construção simbólica dos atos violentos e suas consequências}

Analisado o processo de categorização dos torcedores vinculados a atos violentos, considero importante examinar como foram simbolicamente construídas as açōes atribuídas a eles e as consequências destas sobre os outros.

\section{Dramatização}

Para convencer o leitor da gravidade da violência no futebol brasileiro, a maioria dos textos analisados desenvolve uma narrativa específica, que associa essa violência a uma dimensão dramática, enfatizando o caráter extremo e hediondo de suas consequências ${ }^{42}$. A dramatização serve, portanto, para evidenciar o sofrimento humano produzido pelo problema em questão. Entre outras formas, essa narrativa é construída através do uso recorrente de palavras e expressões que evocam imagens fortes e que estimulam o sentimento de medo e aversão em relação aos torcedores vinculados a atos violentos e de solidariedade e compaixão em relação às suas (supostas) vítimas, ajudando a dar forma ao "drama" vivido por elas. Assim, ao mesmo tempo em que ajuda a criar uma "auréola de dignidade e moralidade" em torno dessas (supostas) vítimas, a dramatização ajuda a caracterizar os referidos torcedores como personagens detestáveis.

No processo de construção de tal narrativa, observei que diversos artigos recorrem ao uso de uma série de adjetivos e advérbios que operam como elementos avaliadores, com conotação negativa latente. Nos fragmentos a seguir, o advérbio "covardemente" e os adjetivos "deprimentes", "chocantes", "preocupantes" e "degradantes" acrescentam aos episódios descritos a desaprovação dos autores:

[...] as cenas vistas na TV de mais uma briga entre torcedores no clássico paulista foram deprimentes! Um torcedor morreu após levar um tiro na cabeça. O outro foi covardemente espancado. Por sinal, imagens essas chocantes, em que um torcedor do São Paulo caído no meio da rua recebeu durante vários minutos uma enorme quantidade de chutes na cabeça ${ }^{43}$.

Dois fatos especialmente degradantes ocorridos no fim do Campeonato Brasileiro de futebol são preocupantes: os atos de vandalismo em Curitiba, no estádio Couto Pereira, e os tumultos nas filas para a compra de ingressos para o jogo Flamengo x Grêmio, no Maracană ${ }^{44}$.

Também notei o uso recorrente de um substantivo em particular: "selvageria". Este aparece, por exemplo, em um texto de Benjamin BACK ${ }^{45}$ : "nada justifica aqueles atos covardes de vandalismo e selvageria, afinal, o Coxa perdeu na bola." "Selvageria" denota "irracionalidade" e sugere que a violência no futebol é "sem propósito" - o que serve para torná-la ainda mais condenável e revestir seus protagonistas com a imagem da maldade, já que nada explicaria aquilo que fizeram.

Outra estratégia adotada na construção do "drama" da violência no futebol brasileiro é a estratégia do deslocamento, que transfere para um evento as conotaçōes positivas ou negativas de outro. $\mathrm{O}$ extrato a seguir é ilustrativo e transfere as conotações negativas dos conflitos que ocorrem na Faixa de Gaza para o conflito ocorrido entre corintianos e policiais no Morumbi: "é preciso muito mais do que [...] se revoltar com os pares de tênis que sobraram na entrada de acesso da arquibancada no Morumbi onde corintianos e policiais pareciam israelenses e palestinos na Faixa de Gaza" ${ }^{36}$.

Também notei que, em alguns momentos, recorrese ao uso de hipérboles: "o estádio de futebol e seus arredores viraram faixas de ódio, de covardia coletiva, de extravasamento da idiotia e do que de mais sombrio pulsa na alma humana, embora, registre-se, seja a minoria dos torcedores que assuma tal papel” ${ }^{37}$. Aqui, o emprego da linguagem hiperbólica reveste os 
estádios com a imagem do dantesco. Imagem que, ao mesmo tempo em que contribui para estigmatizar os torcedores percebidos como violentos, ajuda a criar um sentimento de inaceitabilidade em relação à situação de suas (supostas) vítimas. Além da hipérbole, é possível observar o emprego de diversas outras figuras de linguagem como uma estratégia para caracterizar as açôes promovidas pelos torcedores vinculados a ações violentas e as consequências destas açôes sobre os outros torcedores e sobre o restante da sociedade. Entre as figuras de linguagem mais aplicadas no material analisado, destaco a metáfora.

\section{Metáforas}

De acordo com THOMPSON ${ }^{3}$ (p.85), "a metáfora implica a aplicação de um termo ou frase a um objeto ou ação à qual ele, literalmente, não pode ser aplicado." Mais exatamente, a metáfora levanta "[...] uma tensão dentro de uma sentença, através da combinação de termos extraídos de campos semânticos diferentes, tensão essa que, se bem sucedida, gera um sentido novo e duradouro" (p.85). Entre outras metáforas, observei o emprego sistemático da "metáfora da guerra", que é expressa nos seguintes exemplos: "a única medida prática após a guerra entre a polícia e a torcida do Corinthians, domingo passado, foi a indicação do promotor Arnaldo Hossepian Júnior para apurar o que houve no Morumbi" ${ }^{77}$ (grifo meu). "A semana foi marcada pela morte de um torcedor e de não sei quantos feridos numa batalha sem o menor sentido, em que os vencedores não conquistaram absolutamente nada, nem para eles nem para os seus clubes. Foi um caso escandaloso de violência pela violência" ${ }^{48}$ (grifos meus). "E pior: além de um ônibus queimado no Pacaembu e de dezenas de torcedores detidos por uma guerra na Marginal Tietê, um torcedor foi assassinado. Mais um..." ${ }^{32}$ (grifos meus). "Vândalos, baderneiros - como queiram chamar protagonizaram cenas de guerra em um estádio de futebol”49 (grifo meu). "São brasileiros corajosos que se arriscam a sair de casa para ir aos estádios. Mas as arenas, que deveriam ser palcos de emoções, estão se transformando em campo de batalha" 50 (grifos meus). "O ambiente profissional que aos poucos vai se implantando no futebol não poderia permitir, por exemplo, que os clubes de futebol fossem reféns de suas próprias torcidas organizadas e não tomassem medidas com medo de retaliação" "O governador fluminense, Sérgio Cabral, gosta de futebol, é vascaíno militante e desconhece que o
Maracanã é uma praça de guerra" ${ }^{2}$ (grifo meu). "Deixamos o estádio virar front" 53 (grifo meu).

A metáfora da guerra, tanto real como latente, é reforçada semanticamente pelo emprego de uma série de vocábulos normalmente utilizados para descrever ou evocar esse tipo de situação, tais como: o adjetivo "corajosos", o verbo "arriscar", os substantivos "batalha", "campo de batalha", "morte", "medo", "violência", "feridos", "reféns", "front" etc. Ao sugerir uma relação de semelhança entre os estádios de futebol e uma praça de guerra, a metáfora em questão reveste esses espaços com a imagem da hostilidade, da desordem e do perigo, ao mesmo tempo em que oculta outras características tradicionalmente imputadas a eles: como a festa, a alegria e a celebração.

Em um dos trechos destacados, essa metáfora apareceu explicitamente vinculada à noção de gratuidade da violência - "batalha sem o menor sentido", "em caso escandaloso de violência pela violência" 48 . Esta associação é importante de ser destacada uma vez que negligencia as causas históricas, sociais e culturais da violência, o que, conforme já sugeri, evoca a ideia de "maldade inata". Em outro trecho, essa metáfora foi utilizada para descrever o conflito entre torcedores e policiais: "guerra entre a polícia e a torcida do Corinthians" 37 . Posto que estes últimos tendem a ser percebidos como a instituição que visa assegurar " [...] a ordem, a moralidade e a segurança em uma sociedade" 54 (p.2249), a "guerra" dos torcedores contra a polícia pode, por uma questão de inferência, ser estendida à toda a sociedade. Uma guerra "deles" contra "todos nós".

Outra metáfora empregada para se referir aos torcedores violentos, às suas ações e às consequências destas para os outros é a metáfora da geometria, que compara semanticamente essas ações com o campo do espaço e das figuras. Analisemos o seguinte trecho: "não obstante, a cada ano, em cidades como Goiânia, São Paulo ou Belo Horizonte, é possível identificar ao menos uma dezena de mortos que se originam dessa espiral de violência" ${ }^{55}$. De acordo com VASILACHIS DE GIALDino ${ }^{56}$ (p.145, tradução minha), o termo "espiral" refere-se "[...] a uma linha curva, plana aberta, que dá indefinidamente voltas ao redor de um ponto distanciando-se mais dele em cada uma delas." Diante disto, podemos dizer que a aplicação da metáfora da geometria sugere aqui que o fenômeno da violência no futebol se mostra em rápida, contínua e constante expansão, podendo alcançar consequências inesperadas e imprevisíveis. O que, certamente, contribui para aumentar sua importância e gravidade; sua dimensão dramática e trágica. 
Uma terceira metáfora empregada é a da natureza, que identifica o torcedor vinculado a atos violentos em termos de açôes animalescas e/ou patológicas: "com certeza esses animais não representam a grande maioria da torcida do Coritiba, no entanto, por causa de alguns, todos infelizmente vão pagar"34 (grifo meu). "É preciso combater o lado podre. Não, eliminar o doente para extirpar a doença" 57 (grifos meus). "Com a mudança na lei e na atitude da Justiça e da polícia, as organizadas terão de se civilizar na marra, incorporando-se à sociedade e deixando de ser as aterrorizantes excrescências que se transformaram"39 (grifo meu). Classificados de "animais", "lado podre", "aterrorizantes excrescências", os torcedores em questão seriam a "doença" do futebol e, por esta razão, deveriam ser extirpados ou se incorporar à sociedade. Aqui, o mundo social é equiparado a um organismo vivo, "[...] como um sistema que persiste em virtude da propensão espontânea de seus componentes a manter o funcionamento desse sistema como unidade" ${ }^{56}$ (p.144, tradução minha). Trata-se, portanto, de uma interpretação da vida humana como um sistema de tipo orgânico, onde as partes e elementos estão em relação funcional com o todo, determinando e sendo determinado por ele ${ }^{58}$. Nesse sentido, o futebol é apresentado de um ponto de vista biológico, como se ele padecesse de uma enfermidade, no caso a violência praticada por torcedores. Estes são construídos como corpos estranhos que devem ser extraídos do "corpo social".

Seja através da animalização ou da patologização do comportamento violento, a metáfora da natureza expulsa esse comportamento do campo racional, retirando seu aspecto propriamente humano. Ao fazer isto, contrapõe-se, em certo sentido, à metáfora da guerra, visto que a organização em termos de atitude bélica geralmente supõe uma forte racionalidade ${ }^{59}$. Nesse sentido, essas metáforas acabam produzindo um paradoxo dentro do debate em questão: a violência é, ao mesmo tempo, interpretada como racional e irracional. Em comum, elas reforçam o processo de estigmatização do torcedor percebido como violento, já que o mantém como protagonista de situaçôes letais, destrutivas e cruéis, sem problematizar as condiçôes que mobilizam suas açôes, o que pode contribuir para alimentar a ideologia, conforme discutirei melhor a seguir.

\section{Interpretação/ reinterpretação do debate}

O processo de interpretação desenvolvido aqui é simultaneamente um processo de reinterpretação, afinal os artigos analisados são parte de um "campo pré-interpretado", participando de, e dialogando com, um debate que possui história. E como todo processo de reinterpretação, este é arriscado, cheio de conflitos e aberto à discussão, podendo diferir das visões dos envolvidos no debate em questão. Nesse sentido, minha reinterpretação pode contribuir para a transformação interpretativa da violência no futebol brasileiro. Mais ainda, dado que essa reinterpretação está aberta a uma reflexão crítica sobre as relações de dominação que caracterizam o universo do futebol, em particular, e a sociedade, em geral, ela contém uma ligação estreita com o que podemos chamar de crítica da dominação.

A primeira crítica a ser feita diz respeito ao fato de a violência, em geral, não ser interpretada como o resultado de um acontecimento social, histórico e cultural, mas atribuída a um defeito moral ou de caráter. Com isso, o debate perde em conhecimento sobre as especificidades de vida que levam os torcedores vistos como violentos a agirem violentamente, tornando mais difícil qualquer possibilidade de empatia. Esse torcedor é o "outro", aquele que deve ser combatido e eliminado.
Ao mesmo tempo em que ajuda a estigmatizá-lo, essa abordagem dificulta a possibilidade de construção de iniciativas de aproximação, diálogo, confiança e convivência para evitar mais violência. Mais ainda, ela encobre a responsabilidade do Estado na construção de seus comportamentos e atitudes, contribuindo para manter a ordem social do jeito que está. Nesse sentido, ela pode ser considerada ideológica.

Mas, talvez, ainda mais grave seja o fato de tal estigma atingir diretamente a identidade social dos torcedores organizados. Em primeiro lugar, porque ajuda a legitimar mecanismos legais de controle e penalização específicos para esses torcedores, convertendo-os em sujeitos com menos direitos do que outros. Conforme notei na contextualização do debate, atualmente existe uma série de dispositivos legais que contribuem para a sua criminalização. Estes, todavia, em nenhum momento foram criticados pelos artigos jornalísticos. Pelo contrário, em geral, quando abordados, foram avaliados positivamente. $\mathrm{O}$ estigma opera justamente desta forma: desumaniza e, ao fazer isto, autoriza o controle social sobre aquele que é desumanizado.

Além disso, o processo de estigmatização dos torcedores organizados contribui para diminuir 
o seu poder político. Conforme já indiquei, esses torcedores praticamente não possuem voz na mídia nem em outros lugares onde é realizado o debate público em questão. Não é difícil inferir que o descrédito estabelecido em relação a eles subtrai seu "direito à palavra": faz deles uma fonte de informação e reflexão ilegítima e, por isso, não consultada. E, mesmo nos casos em que eles são consultados, sua palavra perde em força simbólica, pois é contaminada por esse descrédito. Nesse sentido, ao enfraquecer ou, até mesmo, destruir a reputação dos torcedores organizados, os discursos que os estigmatizam contribuem para minar sua credibilidade e, consequentemente, reduzir sua capacidade de mobilizar apoio e de interferir nos processos decisórios acerca das políticas de contenção da violência no futebol, em particular, e nos arranjos institucionais do futebol profissional, de uma maneira geral ${ }^{\mathrm{n}}$. Ao fazerem isso, esses discursos mantêm os torcedores organizados em uma situação de dominação e, por esta razão, possuem uma dimensão ideológica.

Ao abordar o debate público acerca da violência no futebol brasileiro, busquei, portanto, mostrar que, a despeito de muitas vezes se revestirem de um "verniz humanitário", diversos dos discursos nele enunciados estão, na verdade, a serviço da dominação. Para tanto, analisei e interpretei a categoria "torcedor violento" a partir de um quadro teórico-metodológico alternativo. Embora a crítica da ideologia receba, há tempos, a atenção de alguns autores que pesquisam o futebol, a teoria proposta por THOMPSON ${ }^{3}$ ainda é muito pouco utilizada nesse campo de investigação, diferindo-se significativamente daqueles referenciais que embasam alguns estudos clássicos sobre futebol e ideologia ${ }^{\circ}$. Conforme já indiquei, o autor não reduz a ideologia a um mero conjunto de imagens e ideias que invertem e distorcem a "realidade social". Pelo contrário, ele esboça um campo mais rico de análise, indicando um amplo raio de possibilidades para a operação da ideologia. Com isso, pude, entre outras coisas, identificar e analisar diferentes estratégias de construção simbólica (como o estigma e a metáfora), que se sobrepõem e se reforçam mutuamente, contribuindo para a manutenção de certas relações de dominação.

Ao enfatizar a importância da crítica da ideologia para a compreensão da violência envolvendo torcedores de futebol, conferindo um lugar de destaque para a questão da dominação, busquei analisar esse tema sob um novo ângulo. Afinal, grande parte das produçôes (brasileiras e estrangeiras) tem procurado responder questôes como: quais são as causas dessa violência? O que deveria ser feito para reduzi-la? Ou seja, elas têm enfocado o comportamento violento de alguns grupos de torcedores, variando naquilo que julgam serem as suas causas principais e soluçōes mais adequadas. Embora reconheça que esse tipo de questionamento seja social e cientificamente relevante, penso que os estudos sobre o tema devem dar maior ênfase àqueles que enunciam e denunciam a violência em questão, ou seja, àqueles que debatem e formulam as pautas sobre o assunto, não lhes oferecendo, como busquei fazer aqui, nenhuma isenção convencional de indagação e análise, por mais respeitáveis ou altamente situáveis que sejam ${ }^{60}$.

Tampouco devemos isentar esses atores da responsabilidade sobre seus discursos e suas (prováveis) consequências. $\mathrm{O}$ fato de nenhuma produção discursiva ser ideológica em si mesma não pode, em hipótese alguma, servir de desculpa para uma prática discursiva discriminatória e irresponsável. Até mesmo porque é possível ter certa compreensão geral de como, no atual cenário do futebol brasileiro, a ideologia é mobilizada através de determinadas construçôes discursivas. Conforme tentei demonstrar ao longo deste trabalho, há pouca dúvida, por exemplo, que a repetida ênfase e o enfoque nas características desviantes ou criminais dos torcedores organizados criam e confirmam atitudes discriminatórias contra esse torcedor. Assim, parece-me fundamental que o referido debate seja sempre orientado por princípios éticos, que devem evitar os impactos eventualmente degradantes de alguns discursos sobre os grupos dominados ${ }^{61}$.

Para "virar o jogo" em favor desses grupos, é preciso, também, uma mudança na estrutura do próprio debate. Este não deve ficar a cargo de alguns poucos "especialistas", pois se não existem regras preestabelecidas através das quais possamos responder com certeza se as políticas de segurança para os espetáculos futebolísticos são de fato justas, podemos nos aventurar a afirmar que elas, para serem merecedoras de apoio, devem contar com a participação efetiva de todos os grupos sociais por elas afetados ${ }^{3}$. Diante disto, finalizo este artigo com a esperança de que, num futuro próximo, seja dado mais espaço aqueles grupos que habitualmente são excluídos das posiçôes de poder. Definitivamente, estes devem ser mais considerados nos acordos e nas decisōes sobre os rumos do esporte no país. 


\section{Notas}

a. Como o "Seminário sobre Segurança nos Estádios", promovido, em 2003, pelos Ministérios do Esporte e da Justiça, e o seminário "Estádios, Segurança e condiçōes de uso", promovido, em 2009, pelo Ministério dos Esportes, pelo Conselho Nacional de Justiça (CNJ) e pela Confederação Brasileira de Futebol (CBF). Sobre esses eventos, sugiro a leitura de REIS ${ }^{62-63}$.

b. Desse modo, não é possível, a partir do referencial teórico adotado, discutir ideologia no debate público sobre violência no futebol sem levar em consideração as tensões, contradições e assimetrias que caracterizam o contexto em que ele está inserido. No entanto, essas tensões, contradições e assimetrias raramente são indicadas nos discursos pesquisados, já que um dos principais modos de operação da ideologia é justamente a dissimulação. Frequentemente, as relações de dominação no universo do futebol são estabelecidas e sustentadas pelo fato de serem ocultadas, negadas ou apagadas ${ }^{64}$. Por esta razão, não apresento, ao longo do trabalho, discursos que reforcem essa caracterização. Contudo, conforme veremos adiante, faço isto a partir da literatura acadêmica disponível.

c. Tal iniciativa resultou no surgimento da Associação das Torcidas Organizadas do Rio de Janeiro (ASTORJ), que propunha formalizar a relação entre as torcidas e legitimá-las como uma força corporativa com influência na estrutura de poder do futebol. A ASTORJ existiu oficialmente até meados da década de $90^{7}$.

d. Como a Torcida Organizada do Fluminense (TOF) e a Torcida Organizada do Vasco (TOV).

e. Como a Charanga do Flamengo e as torcidas uniformizadas de São Paulo.

f. A Mancha-Verde foi extinta em 1995, após alguns de seus integrantes entrarem em conflito com integrantes da Torcida Independente, do São Paulo, durante a chamada "batalha campal do Pacaembu", tema que retomarei a seguir. Em 1997, ex-integrantes da torcida fundaram a Mancha-Alviverde, desvinculada juridicamente da Mancha-Verde. Ainda que haja essa desvinculação, a Mancha-Alviverde é vista por alguns autores como uma continuação da Mancha-Verde. Para MURAD ${ }^{65}$, por exemplo, esta última nunca deixou de existir na prática.

g. Trata-se do número de fatalidades ligadas ao futebol, mesmo que indiretamente.

h. São Paulo é o Estado com maior número de mortes: 17. Mesmo número de óbitos somados em três Estados: Minas Gerais (7), Rio de Janeiro (5) e Rio Grande do Sul (4) ${ }^{12}$.

i. De acordo com a proposta, para assistir a uma partida, todo torcedor maior de 16 anos teria de apresentar na entrada um cartão magnético no qual estaria registrada sua impressão digital.

j. O próprio ministro abordou o tema em artigo publicado na Folha de S. Paulo, conforme pude observar na análise do material selecionado, que será descrito a seguir.

k. A escolha por trabalhar com esses três bancos de dados deveu-se a motivos variados. No caso do banco virtual da Folha de S. Paulo, ela se justifica uma vez que ele disponibiliza todo o acervo do jornal. Para encontrar o material desejado, utilizei e cruzei os seguintes descritores: agressão, comportamento violento, Estatuto do Torcedor, futebol, legislação esportiva, massa, multidão, rivalidade, torcedor, torcida organizada, torcida uniformizada, vandalismo e violência. A escolha pelo acervo do Arquivo Público do Estado de São Paulo, por sua vez, justifica-se uma vez que se trata de um dos arquivos públicos mais completos do país, disponibilizando todas as edições do Lance! até o final de 2009. Já a opção pelo meu arquivo pessoal justifica-se pelo fato de ele ter possibilitado o acesso às ediçôes de 2010 desse mesmo jornal. Aqui, cabe observar que essas edições não foram encontradas em acervos públicos. No momento da consulta, o acervo da biblioteca Mário de Andrade, por exemplo, disponibilizava apenas os números publicados até 2007. Também cabe observar que, tanto no Arquivo Público do Estado de São Paulo quanto no meu arquivo pessoal, os artigos foram, primeiramente, selecionados a partir dos seus títulos, que deveriam conter ao menos um dos descritores supracitados. Este critério, no entanto, mostrou-se insuficiente, pois, ainda que alguns textos não apresentassem títulos com esses descritores, as imagens que os acompanhavam e/ou o vocabulário utilizado nos títulos, subtítulos e lides ("leads") indicavam que ele abordava a questão da violência no futebol. Nestes casos, os elementos presentes no conteúdo do corpo do texto serviram como critério final de inclusão ou exclusão.

1. Todavia, é preciso observar que estes últimos, em geral, seguem a linha editorial do jornal. Primeiro, porque um jornal costuma dar voz somente àqueles que compartilham de seus princípios e interesses - sobretudo econômicos. Segundo, porque se ocorre a um articulista fixo (que é funcionários do jornal) contradizer em seus textos a opinião oficial do jornal, ele sabe que poderá perder o emprego ${ }^{21}$.

m. A Scientific Electronic Library Online (www.scielo.org); CD-ROM "Levantamento da produção sobre o futebol nas ciências humanas e sociais de 1980 a 2007”; Banco de Teses da CAPES (http://www.capes.gov.br/servicos/bancoteses. html); Biblioteca Central da Universidade Presbiteriana Mackenzie (http://www.mackenzie.br/bibliotecas); Biblioteca da Universidade Estadual de Campinas (http://www.sbu.unicamp.br); Biblioteca da Universidade de São Paulo (http:// dedalus.usp.br); Biblioteca da Universitat Autònoma de Barcelona (http://www.uab.cat/bib/); Biblioteca Karl A. Boedecker 
da FGV-SP (http://www.fgvsp.br/biblioteca); Biblioteca Nadir G. Kfouri da PUC-SP (http://biblio.pucsp.br). A escolha desses bancos de dados deveu-se a motivos variados. O site da Coordenação de Aperfeiçoamento do Pessoal de Nível Superior (CAPES) foi escolhido uma vez que ele permite o acesso aos resumos de todas as teses e dissertaçóes defendidas no país desde 1987. O site SciELO, por sua vez, é uma biblioteca eletrônica de referência, que abrange uma vasta coleção de periódicos científicos brasileiros e de outros países da América Latina e Caribe. Já as bibliotecas da USP, PUC-SP, FGV-SP, Mackenzie e UNICAMP, além de serem de referência, estão localizadas na cidade de São Paulo, onde foi realizada esta pesquisa, ou próxima dela. Afora isto, possuem em seus acervos livros de autores brasileiros e estrangeiros - um importante tipo de produção não disponibilizado nem pelo Banco de Teses da CAPES nem pelo SciELO. A biblioteca da Universidade Autônoma de Barcelona é igualmente de referência, além de ter sido nesta universidade onde o autor deste artigo realizou seu estágio-doutoral. Já o CD-ROM "Levantamento da Produção sobre o Futebol nas 51 Ciências Humanas e Sociais de 1980 a 2007" catalogou 626 trabalhos que tratam do conhecimento relativo ao futebol nas Ciências Humanas e Sociais durante o período de 1987 a 2007, oferecendo um resumo de cada livro, artigo, dissertação e tese catalogados. Finalmente, o arquivo particular do autor possui algumas produções não encontradas em nenhum dos bancos de dados anteriores.

n. Isto se torna ainda mais problemático se considerarmos que algumas das demandas sociais e políticas das torcidas organizadas são altamente contestatórias ao atual processo de elitização do futebol brasileiro - expresso, por exemplo, no aumento abusivo do preço dos ingressos.

o. Tais como o desenvolvido por Roberto RAMOs ${ }^{66}$, que entende o futebol como sendo um aparelho ideológico do Estado, que mistifica a "realidade" e legitima o modo de produção capitalista.

\begin{abstract}
Ideological dimensions of the public debate about violence in Brazilian football

This study aimed to answer the following question: can the discourses produced in the public debate about violence involving Brazilian football supporters be considered ideological, establishing and maintaining domination relations? The concept of ideology proposed by John B. Thompson was used, as well as his methodology: the depth hermeneutics. Following the traditional structure proposed by this methodology, the study was divided in three interdependent parts: the first one, analyzed the socio-historical context of the debate. Afterwards, its formal and discursive structures are analyzed. Finally, the outputs from the formal and discursive structures were interpreted. It was possible to conclude that the debate discussed here uses a narrative wich stigmatizes the football supporters involved in violent actions, specially the "organized supporters", who are maintained in a domination situation.
\end{abstract}

KEY WORDS: Football; Violence; Ideology; Organized supporters.

\title{
Referências
}

1. Dunning E, Murphy P, Williams J. Spectator violence at football matches: towards a sociological explanations. In: Elias N, Dunning E. Quest for excitement: sport and leisure in the civilizing process. Cambridge: Blackwell; 1993. p. 245-66.

2. Ibañez T. O "giro linguístico". 2a ed. In: Iñiguez L. Manual de análise do discurso em ciências sociais. Petrópolis: Vozes; 2004. p.19-49.

3. Thompson JB. Ideologia e cultura moderna: teoria social e crítica na era dos meios de comunicação de massa. 4a ed. Petrópolis: Vozes; 2000.

4. Rosemberg F, Andrade M. Infância na mídia brasileira e ideologia. In: Jacó-Vilela AM, Sato L, organizadores. Diálogos em psicologia social. Porto Alegre: Evangraf; 2007. p.257-74.

5. Toledo LH. Torcidas organizadas de futebol. Campinas: Autores Associados; 1996.

6. Pimenta CAM. Torcidas organizadas de futebol: violência e auto-afirmação: aspectos da construção das novas relações sociais. Taubaté: Vogal; 1997.

610 • Rev Bras Educ Fís Esporte, (São Paulo) 2013 Out-Dez; 27(4):597-612 
7. Hollanda B. O clube como vontade e representação: o jornalismo esportivo e a formação das torcidas organizadas de futebol do Rio de Janeiro (1967-1988) [tese]. Rio de Janeiro(RJ): Pontifícia Universidade Católica do Rio de Janeiro; 2008.

8. Kfouri J. A emoção Corinthians. São Paulo: Brasiliense; 1983.

9. Florenzano JP. A democracia corinthiana: práticas de liberdade no futebol brasileiro. São Paulo: FAPESP; 2009.

10. Canale V. Torcidas organizadas e seus jovens torcedores: diversidades e normativas do torcer [dissertação]. Campinas(SP): Universidade Estadual de Campinas, Faculdade de Educação Física; 2012.

11. Santos RP. Dos espetáculos de massa às torcidas organizadas: paixão, rito e magia no futebol. São Paulo: Annablume; 2004.

12. L!-IBOPE: violência no futebol já matou 51 torcedores. Lance. 18 ago. 2010. Disponível em: www.lancenet.com.br.

13. Brasil. Lei n. 10.671, de 15 de maio de 2003. Dispõe sobre o Estatuto do Torcedor e dá outras providências. [citado 22 jan. 2011]. Disponível em: http://www.planalto.gov.br/ccivil_03/LEIS/2003/L10.671.htm.

14. Reis HHB. Os espectadores de futebol e a problemática da violência relacionada à organização do espetáculo futebolístico. Rev Paul Educ Fís. 2003;17:85-92.

15. Brasil. Lei n. 12.299, de 27 de julho de 2010. Dispõe sobre medidas de prevenção e repressão aos fenômenos de violência por ocasião de competiçôes esportivas; altera a Lei no 10.671, de 15 de maio de 2003; e dá outras providências. [citado 12 abr. 2011]. Disponível em: http://www.planalto.gov.br/ccivil_03/_Ato2007-2010/2010/Lei/L12299.htm.

16. Klein MA. Preservar o espetáculo garantindo a segurança e o direito à cidadania: relatório final da fase I da Comissão Paz no Esporte. Brasília: Ministério do Esporte e Ministério da Justiça; 2005/2006. [citado 26 jan. 2012]. Disponível em: http://www.esporte.gov.br/arquivos/institucional/relatorioFinalPazEsporte.pdf.

17. São Paulo. Assembleia Legislativa. Lei n. 14.590, de 11 de outubro de 2011. Dispõe sobre a identificação dos frequentadores dos jogos de futebol, a comercialização de ingressos, o uso de mastros de bandeiras, e dá providências correlatas. [citado 30 jan. 2012]. Disponível em: http://www.al.sp.gov.br/repositorio/legislacao/lei/2011/lei\%20n.14.590,\%20 de\%2011.10.2011.htm.

18. Luna S. Planejamento de pesquisa: uma introdução. São Paulo: EDUC; 2006.

19. Spink P. A análise de documentos de domínio público. In: Spink MJ, organizador. Práticas discursivas e produção de sentidos no cotidiano: aproximações teóricas e metodológicas. São Paulo: Cortez; 2002. p. 63-92.

20. Giró X. Enfoques analíticos críticos sobre el discurso de la cobertura informativa de conflictos. In: Telleschi T, Sandoval F, Andrés E, coordinadores. Espacio y tiempo en la globalización: una visión de la transparencia en la información. Toluca: Universita' di Pisa y Comisión Estatal para el Acceso a la Información Pública del Estado de Sinaloa; 2007. p.199-220.

21. Van Dijk TA. La multidisciplinariedad del análisis crítico del discurso: un alegato a favor de la diversidad. In: Wodak R, Meyer M, compiladores. Métodos del análisis crítico del discurso. Barcelona: Editorial Gedisa; 2003. p.143-78.

22. Cerqueira R. Que sirva de exemplo! Lance!. 20 fev. 2009.

23. Tostão. Contradições humanas. Folha de S. Paulo. 18 fev. 2009.

24. Sá X. Túmulo do futebol. Folha de S. Paulo. 5 jun. 2009.

25. Torres S. Segurança nos estádios e respeito ao torcedor. Lance!. 20 dez. 2009.

26. Assaf R. Vigiar, enquadrar e punir. Lance!. 17 mar. 2009.

27. Silva O. É hora de virar o jogo. Folha de S. Paulo. 22 mar. 2009.

28. Gomes LF. Demagogia e irresponsabilidade. Lance!. 17 out. 2010.

29. Wright JR. Violência e omissão. Lance!. 17 fev. 2009.

30. Marinho M. Violência sem fim. Por um lado... Lance!. 7 jun. 2009.

31. Kfouri J. A banalização da morte. Folha de S. Paulo. 25 fev. 2010.

32. Benato M. É possível torcer sem matar ou morrer? Lance!. 7 jun. 2009.

33. Back B. Cartolas organizados. Lance!. 19 fev. 2009.

34. Back B. A punição foi justa, mas... Lance!. 17 fev. 2009.

35. Castilho P. Violência sem fim ...por outro lado... Lance!. 7 jun. 2009.

36. Goffman E. Estigma: notas sobre a manipulação da identidade deteriorada. 4a ed. Rio de Janeiro: Guanabara; 1988.

37. Coelho PV. Os bandidos estão vencendo. Folha de S. Paulo. 22 fev. 2009.

38. Kfouri J. Ira organizada. Folha de S. Paulo. 21 out. 2010.

39. Couto JG. Barbárie e cidadania. Folha de S. Paulo. 27 fev. 2010.

40. Back B. Deram espaço, agora aguentem... Lance!. 3 fev. 2009.

41. Toledo LH. Os sem-política. Folha de S. Paulo. 28 fev. 2010.

42. Loseke DR. Ethos, pathos, and social problems: reflections on formula narratives. In: Holstein J; Miller G, editores. Perspectives on social problems. Stamford: JAI Press; 2000. p.41-54. 
43. Back B. A violência está na impunidade! Lance!. 25 fev. 2010.

44. Torres S. Segurança nos estádios e respeito ao torcedor. Lance!. 20 dez. 2010.

45. Back B. A punição foi justa, mas... Lance!. 17 dez. 2010.

46. Santos F. Salve-se quem puder! Lance!. 18 fev. 2009.

47. Kfouri J. A violência que alimenta. Folha de S. Paulo. 7 jun. 2009.

48. Cabral S. Sonhar não custa nada. Lance!. 7 jun. 2009.

49. Cerqueira R. Que sirva de exemplo! Lance!. 20 dez. 2009.

50. Tuma R. O controle da violência envolve toda a sociedade. Lance!. 5 jul. 2009.

51. Carlezzo E. Tolerância zero no papel. Lance!. 15 ago. 2010.

52. Kfouri J. De quem é a culpa. Folha de S. Paulo. 19 fev. 2009.

53. Beting M. Estádio de sítio. Lance!. 20 fev. 2009.

54. Houaiss A, Villar MS, Franco FMM. Dicionário Houaiss da língua portuguesa. Rio de Janeiro: Objetiva; 2001.

55. Hollanda BB. Torcidas-empresas. Folha de S. Paulo. 28 fev. 2010.

56. Vasilachis De Gialdino I. El lenguaje de la violencia en los medios de comunicación: las otras formas de ser de la violencia y de la prensa escrita. In: Programa de las Naciones Unidas para el Desarrollo. Aportes para la convivencia y la seguridad ciudadana. San Salvador: PNUD; 2004. p.109-61.

57. Portella JL. Jogo de cena. Lance!. 25 fev. 2009.

58. De Horcajo JJ, Uña O. La sociología: textos fundamentales. Madrid: Libertarias; 1996.

59. Alabarces P. et al. "Aguante” y represión: fútbol, violencia y política en la Argentina. In: Alabarces P, coordenador. Peligro de gol: estudios sobre deporte y sociedad en América Latina. Buenos Aires: CLACSO; 2000. p.211-30.

60. Becker H. Outsiders: estudos de sociologia do desvio. Rio de Janeiro: Jorge Zahar; 2008.

61. Andrade L. Prostituição infanto-juvenil na mídia: estigmatização e ideologia. São Paulo: EDUC; 2004.

62. Reis HHB. Futebol e violência. Campinas: Armazem do Ipê; 2006.

63. Reis HHB O espetáculo futebolístico e o Estatuto de Defesa do Torcedor. Rev Bras Ciênc Esporte. 2010;31:111-30.

64. Lopes FTP. Discursos sobre violência envolvendo torcedores de futebol: ideologia e crítica na construção de um problema social [tese]. São Paulo(SP): Universidade de São Paulo, Instituto de Psicologia; 2012.

65. Murad M. A violência e o futebol: dos estudos clássicos aos dias de hoje. Rio de Janeiro: FGV; 2007.

66. Ramos R. Futebol: ideologia do poder. Petrópolis: Vozes; 1984.

\title{
Agradecimentos
}

O autor agradece o apoio financeiro recebido pela CAPES (BEX 0247/10-3) e CNPq (140928/2008-1).

\author{
ENDEREÇO \\ Felipe Tavares Paes Lopes \\ Faculdade de Educação Física \\ Universidade Estadual de Campinas \\ Av. Érico Veríssimo, 701 \\ 13083-851 - Campinas - SP - BRASIL \\ e-mail: ftlopes@yahoo.com.br \\ Recebido para publicação: 12/10/2012 \\ 1a. Revisão: 25/03/2013 \\ 2a. Revisão: 18/07/2013 \\ Aceito: 20/07/2013
}

